\title{
The effect of underlying diabetes disease on clinical outcome and survival in patients with Covid-19: a propensity score matching study
}

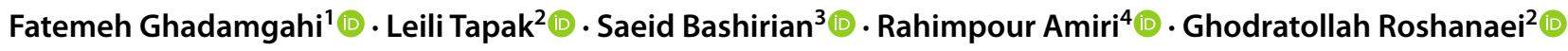

Received: 25 July 2021 / Accepted: 16 October 2021 / Published online: 30 October 2021

(c) Springer Nature Switzerland AG 2021

\begin{abstract}
Purpose Coronavirus increases mortality rate in people with underlying disease. The purpose of the present research was to compare the clinical outcomes in Covid-19 patients with and without underlying diabetes disease using propensity score matching.

Methods A matched case-control study was conducted on 459 diabetic patients with Covid-19 (case group) and 459 nondiabetic patients with Covid-19 (control group). Matching in two groups was performed using propensity score matching method. The effect of covariates on the clinical outcome of the patients (recovery-death) was assessed using logistic regression and the associations of factors with the patients' survival were determined using Cox proportional hazards regression model. Data were analyzed using R software.

Results The mean (standard deviation) age of patients in the case and control groups were 65.77 (12.2) and 65.8 (12.24), respectively. 196 patients (43\%) in the case group, and 249 patients (54\%) in the control group were male (with P-value $<0.05$ ). The logistic regression model showed that the variables of age, level of blood oxygen (SpO2), ICU admission, length of hospitalization, cancer and diabetes affected patients' death. Furthermore, the resuts of the Cox regression showed that the variables of age, level of blood oxygen (SpO2), ICU admission,cancer and diabetes were related to survival of the patients. It was found that diabetes was significantly associated with mortality from COVID-19 with odds ratio of 2.88 (95\% CI: 1.80-4.69; $\mathrm{P}<0.01$ ) and hazard ratio of 1.45 (95\% CI: 1.01-2.03; $\mathrm{P}=0.05$ ).

Conclusion The underlying diabetes significantly increases the mortality among patients with Covid-19, so special care should be taken for this high risk group if they develop Covid-19.
\end{abstract}

Keywords Diabetes $\cdot$ Covid-19 $\cdot$ Logistic regression $\cdot$ Cox regression $\cdot$ Matching $\cdot$ Propensity score

\section{Introduction}

Covid-19 first appeared in China in December 2019 and spread rapidly worldwide, causing a global pandemic [1]. Coronavirus increases mortality in people with underlying

Ghodratollah Roshanaei

gh.roshanaei@umsha.ac.ir

Fatemeh Ghadamgahi

fatemeh.ghadamgahi64@gmail.com

Leili Tapak

1.tapak@umsha.ac.ir

Saeid Bashirian

s-bashirian@umsha.ac.ir

Rahimpour Amiri

r.amiri@umsha.ac.ir disease [2-4]. Because COVID-19 is a new disease and the virus is changing day by day, knowledge about this disease is still incomplete and evolving. Many studies have shown that diabetic patients may experience a more severe clinical course and a higher mortality rate compared to others when

1 Department of Biostatistics, School of Public Health, Hamadan University of Medical Sciences, Hamadan, Iran

2 Department of Biostatistics, School of Public Health, Modeling of Noncommunicable Diseases Research Canter, Hamadan University of Medical Sciences, Hamadan, Iran

3 Social Determinants of Health Research Center, Hamadan University of Medical Sciences, Hamadan, Iran

4 Department of Pediatrics, School of Medicine, Besat Hospital, Hamadan University of Medical Sciences, Hamadan, Iran 
they are infected by COVID-19 [5]. These studies identified diabetes as an important risk factor that increases mortality among Covid- 19 patients [6, 7]. In recent decades, diabetes has been considered as one of the growing epidemics $[8,9]$. Moreover, diabetes is one of the most common underlying diseases for patients with Covid-19 and about $20 \%$ of Covid19 patients suffer from diabetes [10,11]. Diabetes is an important public health problem, and uncontrolled diabetes can lead to many complications in other organs, including loss of vision and kidney dysfunction, heart attacks, strokes, and lower limb amputation, which can lead to disability and death [12]. Therefore, diabetic patients are more prone to certain infectious diseases, probably due to defects in their immune systems [13, 14]. Previous studies have reported that underlying diseases increase the risk of death in patients with Covid-19 [15].

Many studies have been conducted on risk factors of mortality rate among patients with diabetes, nevertheless their results are predisposed to high levels of bias because patients vary in terms of demographic variables, especially age. According to studies [16-18] and experts, the age variable is one of the most important demographic variables in COVID-19 disease. Therefore, the present study aimed to investigate the effect of diabetes on patients' treatment outcomes and assess their affecting factors among patients with Covid-19, using matching patients based on a case-control study in Hamadan.

\section{Materials and methods}

\section{Subjects}

In total, 2459 patients were hospitalized in Sina Hospital in Hamadan, Iran from February 2020 to October 2020 due to COVID-19 disease, of them 459 patients had diabetes (case group). Also, a number of 459 patients out of other 2000 COVID-19 patients who did not have diabetes were selected using the matching method based on age (control group). All demographic characteristics, clinical data, underlying diseases and disease symptoms were extracted from patients' medical records. Moreover, laboratory findings were performed during hospitalization. In this study, two outcomes were considered Including a binaryclinical outcome (death or recovery) and survival time. Survival time was considered as the time from admission to the hospital to death or discharge from the hospital (in days).

\section{Statistical analysis}

Quantitative variables with normal distribution were described by mean and standard deviation (SD), and their means were compared by independent samples t-test.
Qualitative variables were described by frequency (\%) and compared by the Chi-square test or Fisher's exact test in two groups. To minimize any known confounding due to selection bias, the propensity score matching was done. Propensity score matching was performed by the nearest neighbor method with a ratio of $(1: 1)$ based on age variable aiming at to achieve a balanced distribution of all the covariates in the propensity score matched (PSM) cohort. "MatchIt" package (version 4.3.0) was used in R software version 3.6.2 for the propensity score matching, "survival" and "survminer" packages were used for survival analyses. Cox regression model was used to compare the survival of patients in case and control groups and to estimate the hazard ratios (HR). Univariate and multivariate logistic regression was used to estimate the odds ratio (OR) of patients' death and to explore the risk factors of death from COVID-19 among patients with diabetes disease, using "GLM" package. Stepwise regression using backward selection (Wald) method was also utilized to conduct variable selection. The final model only included the variables that contributed signifcantly to the model. Kaplan-Meier curves were plotted (before and after matching) for the time from admission to death (in days) for patients who died. The significance level of the tests was set in $5 \%$.

\section{Results}

In the present matched case-control study, out of 2000 non-diabetic patients, using propensity score matching, 459 non-diabetic patients (control group) compared with 459 diabetes patients (case group). There were 196 men among diabetic patients (case group) and 249 men among non-diabetic patients (control group) $(42.7 \%$ vs $54 / 2 \%, P<0.001$ ). Hypertension $(58.4 \%$ vs $39.2 \%, P<0.001)$ and heart disease ( $28.3 \%$ vs $16.1 \%, P<0.001)$ were more frequent in patients with diabetes, while the median blood oxygen $(\mathrm{SpO} 2)$ was lower $(86 \%$ vs $88 \%, P=0.018)$ in patients with diabetes. The median length of hospital stay and ICU stay were 6 (5) and 3 (1) days, respectively, in the case (control) group $(P<0.001)$. The rate of ICU admission, oxygentherapy, intubation, and death were significantly higher in patients with diabetes compared with the control group $(P<0.001$ for all). There were statistically significant differences in variables of clinical signs of asthma, nausea and vomit $(p<0.05)$. There were no significant differences in other variables after matching (Table 1).

In this study, after data matching, un-adjusted logistic regression was used to identify significant variables associated with the patients' clinical outcomes in two groups (Table 2).

Multivariate logistic regression models were utilized using stepwise backward elimination of insignificant 
Table 1 Demographic and clinical characteristics of the patients

\begin{tabular}{|c|c|c|c|}
\hline Characteristics ID & $\begin{array}{l}\text { Case group } \\
(n=459)\end{array}$ & $\begin{array}{l}\text { Control group } \\
(n=459)\end{array}$ & $p$-value \\
\hline mean(SD))) Age & $65.77(12.24)$ & $65.77(12.24)$ & 1 \\
\hline $\operatorname{Sex}(\operatorname{male}(\%))^{*}$ & $196(0.43)$ & $249(0.54)$ & $<0.01$ \\
\hline Temperature (mean(SD)) & $37.29(0.76)$ & $37.37(0.74)$ & 0.10 \\
\hline Hypertension $(\operatorname{yes}(\%))^{*}$ & $268(0.58)$ & $180(0.39)$ & $<0.01$ \\
\hline Systolic BP (mean(SD)) & $126.25(22.14)$ & $124.21(19.34)$ & 0.14 \\
\hline Diastolic BP (mean(SD) & $76.65(12.96)$ & $76.34(12.25)$ & 0.71 \\
\hline Smoking $($ yes $(\%))$ & $28(0.06)$ & $44(0.09)$ & 0.06 \\
\hline Length of hospitalization $(\operatorname{mean}(\mathrm{SD}))^{*}$ & $8.05(5.91)$ & $6.42(4.47)$ & $<0.01$ \\
\hline $\mathrm{SpO} 2(\operatorname{mean}(\mathrm{SD}))^{*}$ & $82.49(10.84)$ & $84.17(10.70)$ & 0.02 \\
\hline ICU admission $(\text { yes }(\%))^{*}$ & $166(0.36)$ & $125(0.27)$ & $<0.01$ \\
\hline Oxygentherapy (yes $(\%))^{*}$ & $446(0.97)$ & $416(0.91)$ & $<0.01$ \\
\hline Mechanical ventilation $(\text { yes }(\%))^{*}$ & $106(0.23)$ & $50(0.11)$ & $<0.01$ \\
\hline Length of ICU stay (mean(SD))* & $2.88(5.47)$ & $1.63(3.54)$ & $<0.01$ \\
\hline Heart disease $(\operatorname{yes}(\%))^{*}$ & $130(0.28)$ & $74(0.16)$ & $<0.01$ \\
\hline pulmonary disease (yes(\%)) & $54(0.12)$ & $60(0.13)$ & 0.62 \\
\hline Kidney failure (yes(\%)) & $31(0.07)$ & $21(0.04)$ & 0.20 \\
\hline Cancer (yes $(\%))$ & $14(0.03)$ & $17(0.04)$ & 0.71 \\
\hline Other diseases(yes(\%)) & $190(0.41)$ & $172(0.37)$ & 0.25 \\
\hline Asthmatic(yes)(\%)* & $254(0.55)$ & $297(0.65)$ & $<0.01$ \\
\hline Diarrhea(yes)(\%) & $43(0.09)$ & $31(0.07)$ & 0.18 \\
\hline Dry cough(yes)(\%) & $174(0.38)$ & $189(0.41)$ & 0.34 \\
\hline Sputum cough(yes)(\%) & $79(0.17)$ & $86(0.19)$ & 0.61 \\
\hline Muscles pain(yes)(\%) & $189(0.41)$ & $177(0.38)$ & 0.46 \\
\hline Fever(yes)(\%) & $230(0.50)$ & $219(0.48)$ & 0.51 \\
\hline Chills(yes)(\%) & $199(0.43)$ & $196(0.43)$ & 0.89 \\
\hline Sore throat(yes)(\%) & $15(0.03)$ & $27(0.06)$ & 0.08 \\
\hline Nausea(yes)(\%)* & $120(0.26)$ & $83(0.18)$ & $<0.01$ \\
\hline Headache(yes)(\%) & $60(0.13)$ & $77(0.17)$ & 0.14 \\
\hline Fatigue(yes)(\%) & $15(0.03)$ & $16(0.03)$ & 0.99 \\
\hline Vomit(yes)(\%)* & $105(0.23)$ & $66(0.14)$ & $<0.01$ \\
\hline Runny nose(yes)(\%) & 0 & $3(0.01)$ & 0.25 \\
\hline Death $(\%)^{*}$ & $103(0.22)$ & $48(0.11)$ & $<0.01$ \\
\hline
\end{tabular}

*statistically significant variables. In this way, variables with relaxed $P$-value $\leq 0.20$ were included in the multivariate analysis with backward selection approach. The results of multivariate logistic regression were shown in Table 3. The results showed that having chronic diabetes is a factor influencing the clinical outcome of patients with Covid-19. The odds of death in diabetic patients was 2.88 times higher than that of the non-diabetic patients. Also, according to the results of the adjusted regression, in addition to diabetes, variables of age, having cancer, being admitted in ICU, length of hospitalization and $\mathrm{SpO} 2$ were significantly associated with mortality of the patient $(p<0.05)$, so that the odds of death in patients admitted to the ICU were 23.97 times higher than that of the other patients, and the odds of death was 3.32 times higher in patients with cancer compared with the noncancer patients.
Also, a decrease in one unit in blood oxygen (SpO2) level was associated with an increase in the odds of mortality by $4 \%$, and with every one year increase in age and also with every one day increase in the length of hospitalization, the odds of death increasedby $5 \%$. In the above interpretations, other variables in the model were considered to be constant.

Cox regression model was used to examine the effect of diabetes on the survival of patients with Covid-19 considering the time from admission to death (in days). The results of the univariate Cox regression model for the diabetes underlying disease were given in Table 4. Moreover, the results of the multivariate Cox regression model using stepwise backward variable selection method were provided in Table 5 . According to the results, the variables of diabetes, age, having cancer, $\mathrm{SpO} 2$ and ICU admission were significantly 
Table 2 Evaluating the effect of covariates on clinical outcome (mortality) of patients with Covid-19 using univariate logistic regression

\begin{tabular}{|c|c|c|c|c|}
\hline \multirow[t]{2}{*}{ Characteristics ID } & \multirow[t]{2}{*}{ OR } & \multicolumn{2}{|l|}{$95 \% \mathrm{CI}$} & \multirow[t]{2}{*}{$p$-value } \\
\hline & & Lower & Upper & \\
\hline$*$ Age & 1.06 & 1.04 & 1.07 & $<0.01$ \\
\hline Sex & 1.03 & 0.72 & 1.45 & 0.89 \\
\hline Smoking & 1.14 & 0.58 & 2.04 & 0.70 \\
\hline Hypertension(yes)* & 1.64 & 1.15 & 2.32 & 0.01 \\
\hline Temperature & 0.97 & 0.76 & 1.22 & 0.79 \\
\hline Length of hospitalization* & 1.06 & 1.03 & 1.09 & $<0.01$ \\
\hline $\mathrm{SpO} 2 *$ & 0.93 & 0.92 & 0.94 & $<0.01$ \\
\hline ICU admission* & 26.57 & 16.30 & 45.60 & $<0.01$ \\
\hline Oxygentherapy* & 5.64 & 1.73 & 34.70 & 0.02 \\
\hline Mechanical ventilation* & 385.25 & 195.42 & 819.26 & $<0.01$ \\
\hline Length of ICU stay* & 1.18 & 1.14 & 1.22 & $<0.01$ \\
\hline pulmonary disease(yes) & 1.45 & 0.89 & 2.23 & 0.12 \\
\hline Kidney failure(yes) & 1.85 & 0.90 & 3.59 & 0.07 \\
\hline Diabetes(yes)* & 2.50 & 1.72 & 3.57 & $<0.01$ \\
\hline Heart disease(yes)* & 2.38 & 1.64 & 3.45 & $<0.01$ \\
\hline Cancer(yes) & 2.44 & 0.92 & 5.88 & 0.06 \\
\hline Other diseases(yes) & 1.35 & 0.94 & 1.92 & 0.10 \\
\hline Asthmatic(yes) & 1.28 & 0.89 & 1.85 & 0.18 \\
\hline Diarrhea(yes) & 0.78 & 0.37 & 1.49 & 0.48 \\
\hline Dry cough(yes)* & 0.64 & 0.44 & 0.93 & 0.02 \\
\hline Muscles pain(yes) & 0.71 & 0.48 & 1.02 & 0.06 \\
\hline Fever(yes) & 1.01 & 0.88 & 1.43 & 0.98 \\
\hline Chills(yes) & 0.97 & 0.68 & 1.37 & 0.86 \\
\hline Sore throat(yes) & 0.67 & 0.42 & 1.61 & 0.23 \\
\hline Nausea(yes) & 1.12 & 0.73 & 1.69 & 0.58 \\
\hline Vomit(yes) & 0.89 & 0.55 & 1.39 & 0.63 \\
\hline Fatigue(yes) & 1.82 & 0.75 & 4.00 & 0.16 \\
\hline Headache(yes) & 0.85 & 0.50 & 1.39 & 0.53 \\
\hline Sputum cough(yes) & 0.75 & 0.45 & 1.19 & 0.23 \\
\hline
\end{tabular}

*statistically significant

Table 3 Evaluating the adjusted effect of covariates on clinical outcome (mortality) of patients with Covid-19 using multivariate logistic regression

\begin{tabular}{lrrrr}
\hline Characteristics & OR & \multicolumn{2}{c}{$95 \%$ CI } & \multirow{2}{*}{$p$-value } \\
\cline { 3 - 4 } & & Lower & Upper & \\
\hline Age* $^{*}$ & 1.05 & 1.03 & 1.08 & $<0.01$ \\
SpO2* $^{*}$ & 0.96 & 0.94 & 0.98 & $<0.01$ \\
Diabetes(yes)* & 2.88 & 1.80 & 4.69 & $<0.01$ \\
Cancer(yes) & 3.32 & 0.93 & 11.27 & 0.06 \\
ICU admission* & 23.97 & 13.86 & 43.51 & $<0.01$ \\
Length of hospitalization* & 0.96 & 0.92 & 0.99 & 0.02 \\
\hline
\end{tabular}

*statistically significant
Table 4 The results of the univariate Cox regression model

\begin{tabular}{|c|c|c|c|c|}
\hline \multirow[t]{2}{*}{ Characteristics ID } & \multirow[t]{2}{*}{ HR } & \multicolumn{2}{|l|}{$95 \% \mathrm{CI}$} & \multirow[t]{2}{*}{$p$-value } \\
\hline & & Lower & Upper & \\
\hline$*$ Age & 1.04 & 1.02 & 1.05 & $<0.01$ \\
\hline Sex & 1.06 & 0.77 & 1.46 & 0.72 \\
\hline Smoking & 1.08 & 0.61 & 1.90 & 0.80 \\
\hline Hypertension(yes) & 1.24 & 0.90 & 1.72 & 0.19 \\
\hline Temperature & 0.96 & 0.77 & 1.19 & 0.69 \\
\hline $\mathrm{SpO} 2 *$ & 0.96 & 0.95 & 0.97 & $<0.01$ \\
\hline ICU admission* & 7.73 & 4.71 & 12.68 & $<0.01$ \\
\hline Oxygentherapy & 2.27 & 0.56 & 9.23 & 0.25 \\
\hline Mechanical ventilation* & 33.96 & 19.49 & 59.18 & $<0.01$ \\
\hline pulmonary disease(yes) & 1.37 & 0.89 & 2.09 & 0.15 \\
\hline Kidney failure(yes) & 1.74 & 0.96 & 3.15 & 0.06 \\
\hline Diabetes(yes)* & 1.45 & 1.02 & 2.05 & 0.03 \\
\hline Heart disease(yes)* & 1.44 & 1.03 & 2.01 & 0.03 \\
\hline Cancer(yes) & 1.99 & 0.93 & 4.27 & 0.07 \\
\hline Other diseases(yes) & 1.28 & 0.93 & 1.76 & 0.13 \\
\hline Asthmatic(yes) & 1.10 & 0.79 & 1.54 & 0.56 \\
\hline Diarrhea(yes) & 0.81 & 0.43 & 1.54 & 0.52 \\
\hline Dry cough(yes)* & 0.69 & 0.49 & 0.98 & 0.04 \\
\hline Muscles pain(yes) & 0.72 & 0.51 & 1.01 & 0.06 \\
\hline Fever(yes) & 0.97 & 0.71 & 1.34 & 0.86 \\
\hline Chills(yes) & 0.93 & 0.67 & 1.29 & 0.67 \\
\hline Sore throat(yes) & 0.90 & 0.37 & 2.20 & 0.81 \\
\hline Nausea(yes) & 0.87 & 0.60 & 1.27 & 0.47 \\
\hline Vomit(yes) & 0.71 & 0.46 & 1.08 & 0.11 \\
\hline Fatigue(yes) & 1.64 & 0.80 & 3.35 & 0.18 \\
\hline Headache(yes) & 0.92 & 0.57 & 1.47 & 0.73 \\
\hline Sputum cough(yes) & 0.88 & 0.56 & 1.38 & 0.58 \\
\hline
\end{tabular}

Table 5 Evaluating the adjusted effect of covariates on clinical outcome of patients (death, alive) with Covid-19 using multivariate Cox regression model

\begin{tabular}{lllrr}
\hline Characteristics ID & HR & \multicolumn{2}{l}{$95 \%$ CI } & $p$-value \\
\cline { 3 - 4 } & & Lower & Upper & \\
\hline *Age & 1.04 & 1.02 & 1.05 & $<0.01$ \\
SpO2* & 0.96 & 0.95 & 0.97 & $<0.01$ \\
Diabetes(yes)* & 1.45 & 1.01 & 2.03 & 0.05 \\
Cancer(yes)* & 3.03 & 1.37 & 6.66 & $<0.01$ \\
ICU admission* & 7.48 & 4.97 & 11.56 & $<0.01$ \\
\hline
\end{tabular}

*statistically significant

associated with the survival of the patient $(P<0.05)$. The death risk of COVID-19 among the patients with the underlying diabetes was 1.45 times higher than that without diabetes. With every one-year increase in the patient's age and with every one unit increase in the blood oxygen $(\mathrm{SpO} 2)$ 
level, the risk of death increased by $4 \%$, considering other variables constant. The death risk among the patients who were admitted to the ICU were 7.48 times higher than that of the other patients. Furthermore, the survival of the patients before (Fig. 1) and after (Fig. 2) matching in the case and control groups was displayed using the Kaplan-Meier survival analysis plots for the time since admission to death (days) for patients who died from COVID-19. Figure 2 shows that survival rates vary across the two groups after matching, with the diabetes disease patients having lower survival rates. There were 103 deaths among 459 diabetic patients and 48 deaths among 459 non-diabetic patients ( $22 \%$ vs $11 \%, P<0.001)$. The mortality rates of the patients with Covid-19 for other significant variables were shown in Fig. 3. It can be seen from the Fig. 3 that the patients with diabetes, concurrent cancer, being admited to ICU, older than 80 years and having oxygen levels below 80 had higher mortality rates.

\section{Discussion}

Underlying diabetes disease was an important risk factors of mortality in patients with COVID-19.

Because they are a vulnerable population with a higher mortality rate than the general population and need special cares, so in this study, identifyingspecific risk factors of mortality and survival of these patients was performed using appropriate statistical analysis method.

In this study, the clinical outcome in 459 diabetic patients with Covid-19 (case group) was compared with 459 non-diabetic patients (control group) matched using the propensity score method. In the present study, in the univariate model, before adjusting the effect of other variables, the odds of mortality in diabetic patients was 2.50 times higher than that of the non-diabetic patients, so that 103 deaths were observed in diabetic patients and 48 deaths in non-diabetic patients. Various studies from different nations around the world have reported different mortality rates ranging from 8 to $60 \%$ in COVID-19 patients with diabetes underlying disease [19-23]. But none of these studies used data matching methods. Furthermore, some studies have confirmed the relationship between chronic diabetes and mortality in patients with COVID-19 [24, 25]. Guan et al. concluded that COVID-19 patients with any underlying disease had a lower prognosis than other patients [2]. Yan et al. showed that the incidence of death in patients with COVID-19, who also had underlying diseases such as diabetes, hypertension, and heart disease, was significantly higher compared with others [26]. Other studies have also shown that chronic underlying diseases such as hypertension and diabetes may be risk factors for death in patients with COVID-19 [27]. Numerous
Fig. 1 Survival time(day) from admission to death (before PSM)

\section{Strata + diabetes $=0+$ dabetes $=1$}

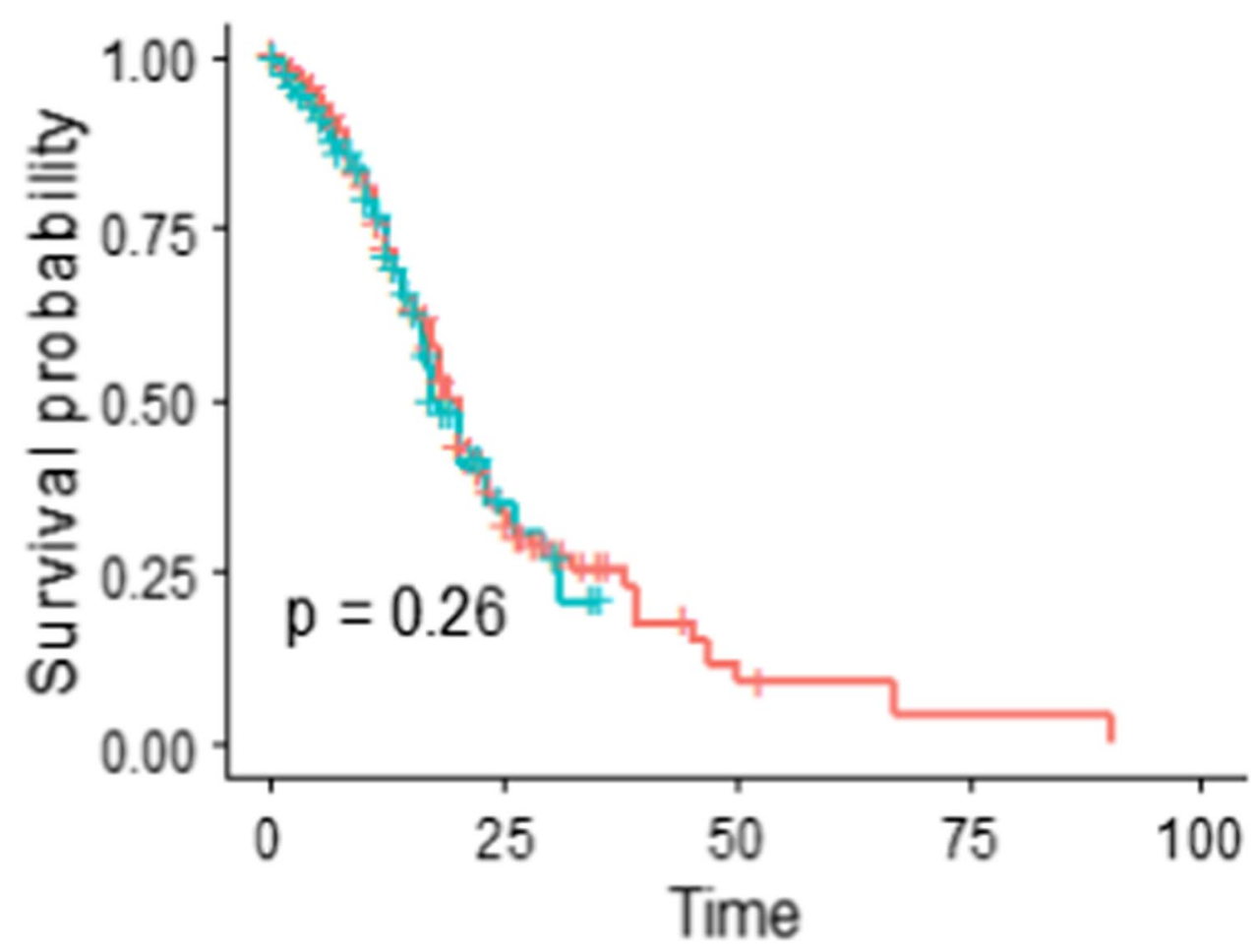


Fig. 2 Survival time from(day) admission to deat (after PSM)

\section{Strata $\div$ diabetes $=0 \div$ diabetes $=1$}

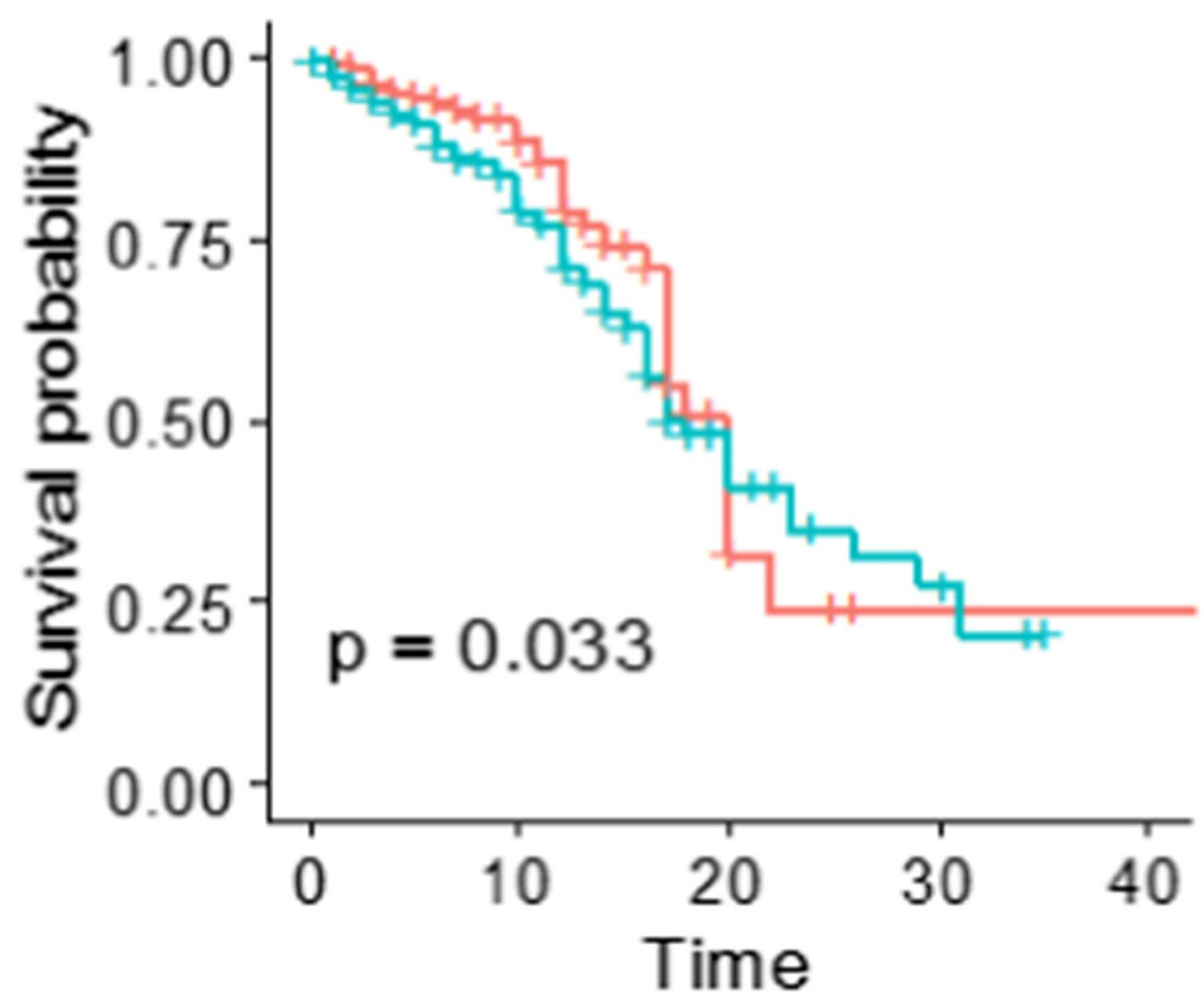

studies have shown that diabetes increases mortality ratein COVID-19 patients [28-32]. Kumar et al. showed that diabetes significantly increases mortality in patients with COVID-19. They indicated that the mortality rate in these patients is 2.16 times higher than the other patients [33]. In this study, despite adjusting the heart disease, cancer, and blood pressure in the case and control groups, the mortality rate of diabetic patients was 2.88 times higher than that of the non-diabetic patients. Rawshani et al. showed that hazard of diabetic patients is 1.50 times higher than that of the nondiabetic patients [34]. In the Sonmez et al. study the hazard ratio of diabetic patients was 1.75 [35]. Also, in the present study, after adjustment of all demographic and clinical variables, the hazard of death in diabetic patients was 1.45 times higher than that of non-diabetic patients.

Our findings, also, showed that ICU admission and length of hospitalization were significantly associated with the mortality of the patients with COVID-19. Moreover, Sonmez et al. showed that length of hospitalization and ICU admission were important variables on patient mortality [35].

Some studies have shown that there is no significant relationship between mortality in patients with COVID-19 and diabetes and the most important cause of mortality in these patients was age $[36,37]$. Older people and people with underlying diseases are more likely to be infected with COVID-19 virus [38, 39]. In the present study, age was associated with increasing risk of death among patients with COVID-19. However, age was matched between the two groups. Despite matching of age in both diabetic and nondiabetic groups, it was concluded that there was a significant relationship between mortality of patients with COVID-19 and age. This may be due to the fact that with increasing age, the immune function of the body decreases [40].

The results of the present study, also, showed that gender was not associated with mortality, which was consistent with the findings of other studies [41-46].

In some studies, clinical signs of patients have been considered as factors affecting patient survival [47]. In some studies, fever and dry cough have been the most important clinical symptoms in patients with COVID-19 [25, 48, 49]. In our study, the most important clinical symptoms of patients were shortness of breath and fever. None of the clinical signs had a significant relationship with the outcome of treatment.

In the present study, the results of logistic regression and also Cox regression showed that blood oxygen (SpO2) levels affect patients' survival. Similarly, Park et al. showed that symptoms such as fever and dry cough are the primary 


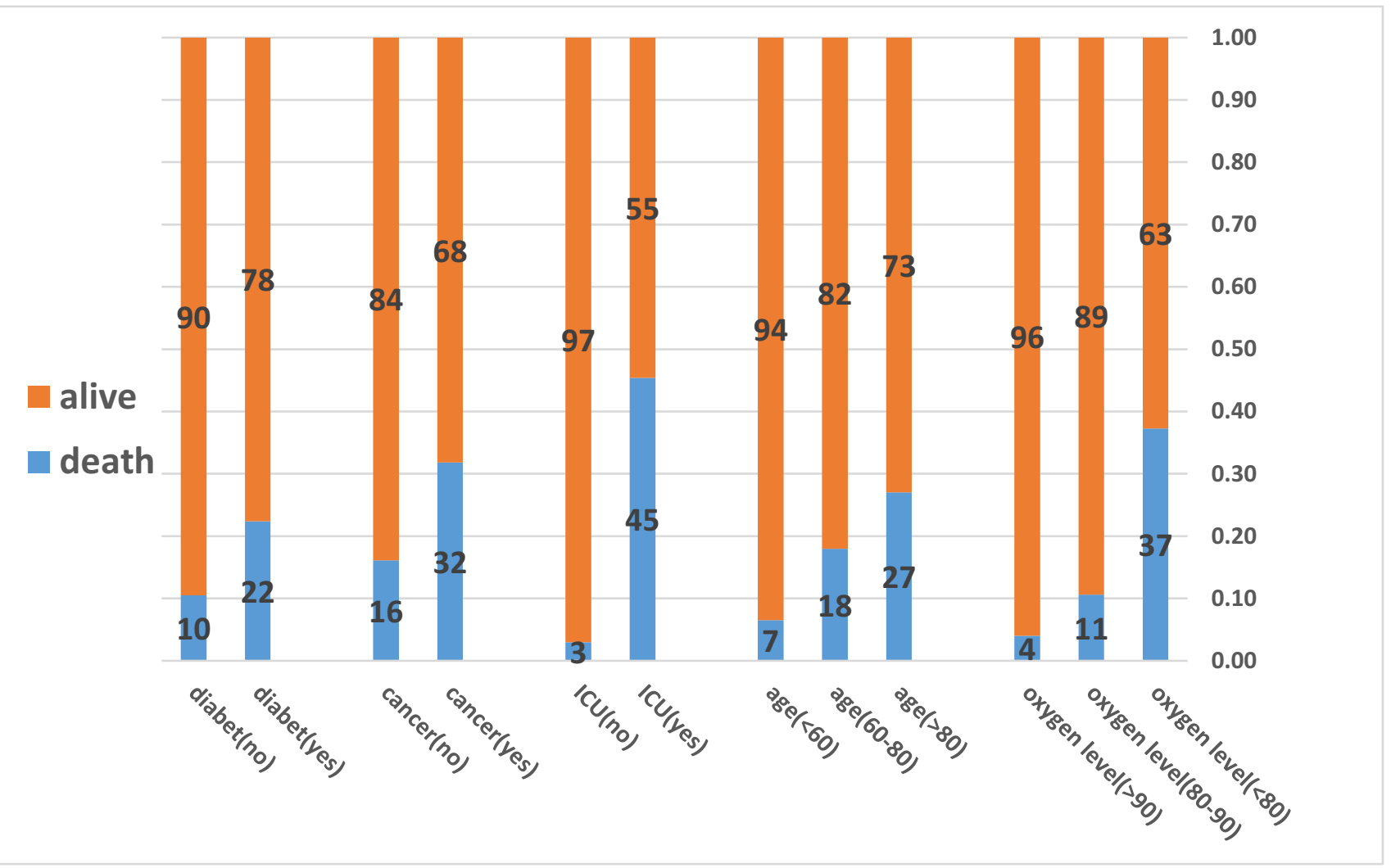

Fig. 3 The percentage of mortality among patients with Covid-19 in term of significant risk factors

causes of COVID-19 disease, but when symptoms become worse and more severe, respiratory symptoms such as shortness of breath and lack of saturated oxygen can cause death [50].

\section{Conclusion}

The results of evaluating the effect of diabetes on the outcome of treatment in patients with COVID-19 after adjusting the clinical and paraclinical characteristics of the variables showed that diabetes affects the mortality of patients. Therefore, they are a vulnerable population with a higher mortality rate than the general population. Thus, screening and identifying these patients and vaccinating them can reduce the mortality rate in these patients.

Acknowledgements We would like to thank the Vice-Chancellor of Research and Technology, Hamadan University of Medical Sciences for the approval and support of the study. This article is part of project number 9912199270 with the specific Ethics ID code IR.UMSHA. REC.1399.1050.

Authors' contributions FG and GR and LT designed the study and analyzed the data. FG and GR wrote the original draft with support from SB and RA. Both FG and GR authors contributed to the interpretation of the results. All authors contributed to the final version of the manuscript and approved the final version of the manuscript.

Data availability The data and materials that supporting the findings of this study are available from the corresponding author, upon request.

\section{Declarations}

Consent to publication All individual participants included in the study gave their informed consent for the inclusion in the study and for publication of the manuscript.

Competing interests We declare no competing interests.

\section{References}

1. Zhu N, Zhang D, Wang W, Li X, Yang B, Song J, et al. A novel coronavirus from patients with pneumonia in China, 2019. N Engl J Med. 2020;382:727-33.

2. Guan W-J, Ni Z-Y, Hu Y, Liang W-H, Ou C-Q, He J-X, et al. Clinical characteristics of coronavirus disease 2019 in China. $\mathrm{N}$ Engl J Med. 2020;382(18):1708-20.

3. Mukherjee S, Pahan K. Is COVID-19 Gender-sensitive? J Neuroimmune Pharmacol. 2021;16(1):38-47.

4. Wu Z, McGoogan JM. Characteristics of and important lessons from the coronavirus disease 2019 (COVID-19) outbreak in China: summary of a report of 72314 cases from the 
Chinese Center for Disease Control and Prevention. JAMA. 2020;323(13):1239-42.

5. Kumar A, Arora A, Sharma P, Anikhindi SA, Bansal N, Singla $\mathrm{V}$, et al. Is diabetes mellitus associated with mortality and severity of COVID-19? A meta-analysis. Diabetes Metab Syndr. 2020;14(4):535-45.

6. Baumann BC, MacArthur KM, Baumann JC. Emotional support animals on commercial flights: a risk to allergic patients. Lancet Respir Med. 2016;4(7):544-5.

7. Gu T, Mack JA, Salvatore M, Sankar SP, Valley TS, Singh K, Nallamothu BK, Kheterpal S, Lisabeth L, Fritsche LG, Mukherjee B. COVID-19 outcomes, risk factors and associations by race: a comprehensive analysis using electronic health records data in Michigan Medicine. JAMA Netw Open. 2020;3(10):e2025197.

8. Saeedi P, Petersohn I, Salpea P, Malanda B, Karuranga S, Unwin $\mathrm{N}$, et al. Global and regional diabetes prevalence estimates for 2019 and projections for 2030 and 2045: Results from the International Diabetes Federation Diabetes Atlas. Diabetes Res Clin Pract. 2019;157:107843.

9. Seidell JC. Obesity, insulin resistance and diabetes-a worldwide epidemic. Br J Nutr. 2000;83(S1):S5-8.

10. Remuzzi A, Remuzzi G. COVID-19 and Italy: what next? Lancet. 2020;395(10231):1225-8.

11. Zhou F, Yu T, Du R, Fan G, Liu Y, Liu Z, et al. Clinical course and risk factors for mortality of adult inpatients with COVID19 in Wuhan, China: a retrospective cohort study. The lancet. 2020;395(10229):1054-62.

12. Organization WH. World malaria report 2015: World Health Organization; 2016.

13. Hodgson K, Morris J, Bridson T, Govan B, Rush C, Ketheesan $\mathrm{N}$. Immunological mechanisms contributing to the double burden of diabetes and intracellular bacterial infections. Immunology. 2015;144(2):171-85.

14. Mufier L, Gorter K, Hak E. Increased risk of common infections in patient With type 1 and type 2 diabetes mellitus. Clin Inlect Dis. 2005;41(3):281-8.

15. Xianming H, Yongzhi D, Jun W, Heping L, Mei L, Zuxun L. Short term outcome and risk factors for mortality in adults with critical severe acute respiratory syndrome (SARS). J Huazhong Univ Sci Technol [Med Sci]. 2004;24(5):514-7.

16. Moghanibashi-Mansourieh A. Assessing the anxiety level of Iranian general population during COVID-19 outbreak. Asian J Psychiatry. 2020;51:102076.

17. McGurnaghan SJ, Weir A, Bishop J, Kennedy S, Blackbourn LA, McAllister DA, et al. Risks of and risk factors for COVID-19 disease in people with diabetes: a cohort study of the total population of Scotland. Lancet Diabetes Endocrinol. 2021;9(2):82-93.

18. Bellino S, Punzo O, Rota MC, Del Manso M, Urdiales AM, Andrianou X, et al. COVID-19 disease severity risk factors for pediatric patients in Italy. Pediatrics. 2020;146(4).

19. Huang I, Lim MA, Pranata R. Diabetes mellitus is associated with increased mortality and severity of disease in COVID-19 pneumonia - a systematic review, meta-analysis, and metaregression. Diabetes Metab Syndr. 2020;14(4):395-403.

20. Cariou B, Hadjadj S, Wargny M, et al. Phenotypic characteristics and prognosis of inpatients with COVID-19 and diabetes: the CORONADO study. Diabetologia. 2020;63(8):1500-1515.

21. Agarwal S, Schechter C, Southern W, Crandall JP, Tomer Y. Preadmission Diabetes-Specific Risk Factors for Mortality in Hospitalized Patients With Diabetes and Coronavirus Disease 2019. Diabetes Care. 2020;43(10):2339-2344.

22. Roncon L, Zuin M, Rigatelli G, Zuliani G. Diabetic patients with COVID-19 infection are at higher risk of ICU admission and poor short-term outcome. J Clin Virol. 2020;127:104354. https://doi. org/10.1016/j.jcv.2020.104354.
23. Zhu L, She Z-G, Cheng X, et al. Association of blood glucose control and outcomes in patients with COVID-19 and preexisting type 2 diabetes. Cell Metab. 2020;31:1068-1077.e3.

24. Wu C, Chen X, Cai Y, Zhou X, Xu S, Huang H, et al. Risk factors associated with acute respiratory distress syndrome and death in patients with coronavirus disease 2019 pneumonia in Wuhan, China. JAMA Internal Med. 2020;180(7):934-43.

25. Xie J, Wu W, Li S, Hu Y, Hu M, Li J, et al. Clinical characteristics and outcomes of critically ill patients with novel coronavirus infectious disease (COVID-19) in China: a retrospective multicenter study. Intensive Care Med. 2020;46(10):1863-72.

26. Yuan M, Yin W, Tao Z, Tan W, Hu Y. Associação de achados radiológicos com mortalidade de pacientes infectados com o novo coronavírus de 2019 em Wuhan, China. PloS one. 2020;15(3):e0230548.

27. Cure E, Cumhur CM. Comment on "Organ-protective effect of angiotensin-converting enzyme 2 and its effect on the prognosis of COVID-19." J Med Virol. 2020;92(9):1423-4.

28. Ahmed FW, Kirresh OZ, Robinson AV, Majeed M, Rouse D, Banatwalla R, et al. A Retrospective Study Assessing the Effect of Diabetes on Mortality in Patients With COVID-19 at a Teaching Hospital in the United Kingdom. Cureus. 2021;13(3).

29. Alshammari KF, Almakhalfi NS, Alradaddi FM, Almutairi MQ, Almeshari RA, Alshammari KF, et al. Effects of COVID 19 Pandemic on Diabetic Patients. J Pharmaceutical Research International. 2021:76-81.

30. Guo W, Li M, Dong Y. Diabetes is a risk factor for the progression and prognosis of COVID-19 [published online March 31, 2020]. Diabetes Metab Res Rev.

31. Hill MA, Mantzoros C, Sowers JR. Commentary: COVID-19 in patients with diabetes. Metabolism. 2020;107:154217.

32. Klonoff DC, Umpierrez GE. Letter to the Editor: COVID-19 in patients with diabetes: Risk factors that increase morbidity. Metabolism. 2020;108:154224.

33. Kumar A, Arora A, Sharma P, Anikhindi SA, Bansal N, Singla $\mathrm{V}$, et al. Is diabetes mellitus associated with mortality and severity of COVID-19? A meta-analysis. Diabetes Metab Syndr. 2020;14(4):535-45.

34. Rawshani A, Kjölhede EA, Rawshani A, Sattar N, Eeg-Olofsson K, Adiels M, et al. Severe COVID-19 in people with type 1 and type 2 diabetes in Sweden: a nationwide retrospective cohort study. Lancet Reg Health-Eur. 2021;4:100105.

35. Sonmez A, Demirci I, Haymana C, Tasci I, Dagdelen S, Salman $\mathrm{S}$, et al. Clinical characteristics and outcomes of COVID-19 in patients with type 2 diabetes in Turkey: A nationwide study (TurCoviDia). J Diabetes. 2021;13(7):585-95.

36. Alkundi A, Mahmoud I, Musa A, Naveed S, Alshawwaf M. Clinical characteristics and outcomes of COVID-19 hospitalized patients with diabetes in the United Kingdom: a retrospective single centre study. Diabetes Res Clin Pract. 2020;165:108263.

37. Yan Y, Yang Y, Wang F, Ren H, Zhang S, Shi X, et al. Clinical characteristics and outcomes of patients with severe covid-19 with diabetes. BMJ Open Diabetes Res Care. 2020;8(1):e001343.

38. Lippi G, Henry BM. Chronic obstructive pulmonary disease is associated with severe coronavirus disease 2019 (COVID-19). Respir Med. 2020;167:105941.

39. Zhao Q, Meng M, Kumar R, Wu Y, Huang J, Lian N, et al. The impact of COPD and smoking history on the severity of COVID-19: A systemic review and meta-analysis. J Med Virol. 2020;92(10):1915-1921.

40. Weiskopf D, Weinberger B, Grubeck-Loebenstein B. The aging of the immune system. Transpl Int. 2009;22(11):1041-50.

41. Chen N, Zhou M, Dong X, Qu J, Gong F, Han Y, et al. Epidemiological and clinical characteristics of 99 cases of 2019 novel coronavirus pneumonia in Wuhan, China: a descriptive study. Lancet. 2020;395(10223):507-13. 
42. Huang C, Wang Y, Li X, Ren L, Zhao J, Hu Y, et al. Clinical features of patients infected with 2019 novel coronavirus in Wuhan, China. Lancet. 2020;395(10223):497-506.

43. Li Q, Guan X, Wu P, Wang X, Zhou L, Tong Y, et al. Early transmission dynamics in Wuhan, China, of novel coronavirus-infected pneumonia. N Engl J Med 2020;382(13):1199-1207. https://doi. org/10.1056/NEJMoa2001316.

44. Meng Y, Lu W, Guo E, Liu J, Yang B, Wu P, et al. Cancer history is an independent risk factor for mortality in hospitalized COVID-19 patients: a propensity score-matched analysis. J Hematol Oncol. 2020;13(1):1-11.

45. Wang D, Hu B, Hu C, Zhu F, Liu X, Zhang J, et al. Clinical characteristics of 138 hospitalized patients with 2019 novel coronavirus-infected pneumonia in Wuhan. China Jama. 2020;323(11):1061-9.

46. Zhang J-J, Dong X, Cao Y-Y, Yuan Y-D, Yang Y-B, Yan Y-Q, et al. Clinical characteristics of 140 patients infected with SARSCoV-2 in Wuhan, China. Allergy. 2020;75(7):1730-41.

47. Liang W, Guan W, Chen R, Wang W, Li J, Xu K, et al. Cancer patients in SARS-CoV-2 infection: a nationwide analysis in China. Lancet Oncol. 2020;21(3):335-7.
48. Tian J, Yuan X, Xiao J, Zhong Q, Yang C, Liu B, et al. Clinical characteristics and risk factors associated with COVID-19 disease severity in patients with cancer in Wuhan, China: a multicentre, retrospective, cohort study. Lancet Oncol. 2020;21(7):893-903.

49. Yang J, Zheng Y, Gou X, Pu K, Chen Z, Guo Q, et al. Prevalence of comorbidities and its effects in patients infected with SARSCoV-2: a systematic review and meta-analysis. Int J Infect Dis. 2020;94:91-95.

50. Park SW, Sun K, Viboud C, Grenfell BT, Dushoff J. Potential role of social distancing in mitigating spread of coronavirus disease, South Korea. Emerg Infect Dis. 2020;26(11):2697.

Publisher's note Springer Nature remains neutral with regard to jurisdictional claims in published maps and institutional affiliations. 